\title{
EFFECT OF RECIPIENT GENOTYPE ON SURVIVAL RATE AT BIRTH OF FROZEN LOCAL RABBIT EMBRYOS
}

\author{
M.A. Abu El-Hamd*; M.A.M. Sheteifa; Sh.M. Shamiah and Ayat, A. Ragab \\ Animal Production Research Institute, Agricultural Research Center, Dokki, Egypt \\ *Corresponding author Email: (abuelhamd68@yahoo.com)
}

\section{SUMMARY}

New Zeland White (NZW) and APRI rabbit strains were used as recipients to study the survival rate at birth of frozen APRI embryos as well as the effect of site of ovary on ovarian activity, ovulation and embryo recovery rates. A total of 18 APRI rabbits line were super-ovulated using PMSG and naturally mated with bucks of the same line. Embryos were collected 64-66 h post coitum and the normal one was examined morphologically before frozing in liquid nitrogen. After thawing, embryos $(n=140)$ were transferred into the oviducts of recipient does of both APRI and NZW does ( $n=8$ both).

Results indicated that no significant effect of the site of ovary on ovulation rate. The percentage of ovulation and recovery rates were higher insignificantly in left ovary by 7 and 11\% than right ovary, respectively. Average number of collected APRI embryos was $12.39 \pm 0.83$ and recovery rate $76.1 \pm 16.2 /$ doe. Examination of ovarian structure indicated that numbers of bleeding follicles, large follicle, and small follicles were $6.22 \pm 1.98,9.89 \pm 2.13$ and $9.56 \pm 2.38$, respectively. Genotype influenced the pregnant rate being $75 \%$ in APRI vs. $50 \%$ in NZW as well as on survival rate, which was about $45 \%$ in APRI and $31.9 \%$ in NZW.

\section{Keyword: Rabbit, breed, frozen embryo, transfer and survival rate}

\section{INTRODUCTION}

The cryopreservation of rabbit genetic resources could be achieved by both males and females germ plasm, through freezing semen and embryos, which are routinely used nowadays. Embryo vitrification permits the rapid cooling with no risk of ice crystal formation in liquid medium (Dobrinsky, 2001). Vitrification is a simple technique and more cheaper than embryo slow rate freezing, however, embryo exposure to high levels of cryoprotectant additives (CPAs) may be deteriorated after devitrification (Leoni et al., 2003).

Several protocols have been developed for the vitrification of rabbit embryos with in vivo satisfaction results (Vicente et al., 1999 and Lópezbéjar and López-Gatius, 2000), with difference rate of after thawing viability (Ogawa and Tomoda, 1976 and Vicente and Garcia- Ximenez, 1993). Strain was reported to affect pregnancy rate of thawed embryos and the general shape of embryos (Ogawa and Tomoda, 1976).

Previous data indicated that about $71 \%$ of vitrified embryos had the ability to be developed to blastocyst stage after in vitro culture for $72 \mathrm{~h}$, and $23.5 \%$ of embryos transferred to four recipients, developed to term (Papis et al., 2005). The study of Vicente (2008) revealed that $50 \%$ of cryopreserved embryos could be survived after transferring, however such percentages are depends on several factors, e.g. stage of embryos, genotype of donors and recipients (Vicente, 2008). The aim of this work was to evaluate the effect of genotype of recipient on the in vivo development of vitrified embryos rabbits.

\section{MATERIALS AND METHODS}

All chemicals used in this study were purchased from Sigma (Madrid, Spain), unless otherwise indicated. Rabbit does of NZW and APRI strains were used in this study as recipients of APRI vitrified embryos. A total of 20 multiparous APRI rabbit does ( $2^{\text {nd }}$ and $3^{\text {rd }}$ parities) was mated to bucks from the same line. After 64-66 hours post-coitum, the donor does were slaughtered and the reproductive tract was removed and the embryos were recovered by flushing with recovery medium (phosphate-buffered saline supplemented with $\mathrm{CaCl}$ (DPBS, Sigma D5773), $0.002 \mathrm{~g} / \mathrm{mL}$ bovine serum albumin (BSA, Sigma A3311), $100 \mathrm{IU} / \mathrm{ml}$ penicillin and $100 \mu \mathrm{g} / \mathrm{ml}$ streptomycin) $(\mathrm{RM})$ at room temperature $\left(20-25^{\circ} \mathrm{C}\right)$. After recovery, embryos were examined morphologically to detect normal ones (morulae with both intact and regular mucin coat and zona pellucida, and homogenous cell mass). Normal embryos from each donor doe were washed twice in fresh RM and kept at room temperature until use (10 to $15 \mathrm{~min}$ ). Ovulation rate (number of luteinized follicles with ovulation stigmas), number of small, large and bleeding follicles and the number of normal and abnormal embryos were recorded as reproductive traits.

A total of 187 embryos at morula stage were vitrified. Vitrification was carried out in two steps at $20^{\circ} \mathrm{C}$. In the first step, embryos were kept for two minutes in $0.4 \mathrm{ml}$ of vitrification solution (VS), $(50 \%$ $\mathrm{RM}+25 \%$ ethylene glycol $+25 \%$ phosphate buffered saline) and RM (VS1) at volume base (1:1) in a plastic culture dish. In the second step, embryos 
were kept in $0.6 \mathrm{ml}$ of the VS $2(20 \% \mathrm{RM}+80 \%$ VS) (vol. /vol.) in a plastic culture dish. The $\mathrm{pH}$ value of the media and osmolarity were adjusted at 7.3-7.4 and 280-300 $\mathrm{mOsmol} / \mathrm{kg}$, respectively before being filtered by $0.22-\mu \mathrm{m}$ millipore filter.

Embryos were suspended in the final vitrification solution and then 8 - 10 embryos were loaded into $0.25-\mathrm{ml}$ plastic straws (IMV, L'Aigle, and France) in 0.1 VS2 solutions. Straws were sealed with polyethylene powder, and then plunged directly into liquid nitrogen. Embryos were exposed to the final vitrification solution for a total of $1 \mathrm{~min}$. The straws contained three fractions separated by air bubbles, the first and third fractions consisted of RM medium, while, the second fraction consisted of VS2 medium.

Devitrification was performed by immersing the second and third sections of the straws in a water bath at $20^{\circ} \mathrm{C}$ for $10-15$ seconds. The cryoprotective solution was removed from the embryos in a twostep dilution procedure at room temperature (20-25 $\left.{ }^{\circ} \mathrm{C}\right)$. The embryos were released into a plastic Petri dish containing $1 \mathrm{ml}$ of $0.33 \mathrm{M}$ sucrose in DPBS medium. After two minutes, the embryos were washed twice in fresh DPBS medium and scored morphologically before transfer. Only embryos with a homogenous cell mass and an intact mucin coat and zona pellucida were transferred $(n=140)$.

A total of 16 multiparous does (APRI $n=8$ and NZW n $=8$ ) does were used as recipients. Ovulation was induced in receptive does 60-64 $\mathrm{h}$ before transfer with an intramuscular dose of 75 IU Human Chrionic Gonadotropin (hCG, Pregnyl, Nile Pharm, Co. Egypt). The recipients were anesthetized by an injection of ketamine solution at the rate of $1.2 \mathrm{ml} / \mathrm{kg}$ body weight. Oviduct embryo transfer was performed unilaterally, where 6 to 14 normal embryos were transferred to each recipient doe. In vivo survival rate was assessed based on birth rates, the number of total offspring born and the number of live offspring.

Number of ovulation (CL), follicles and recovered embryo were compared between the ovarian sites per donor and two recipients using oneway analysis of variance and the recovery rates were compared using Chi-square test.

\section{RESULTS AND DISCUSSION}

Data in Table (1) shows that the ovarian site had no significant effect on the ovarian structure, ovulation and recovery rate of APRI rabbits does. Response of APRI rabbit line to super-ovulation was $90 \%$.

The present results are in agreement with the findings of Ali (2010), who stated that site of ovary did not affect the average number of bleeding follicles and embryo recovery.

Total number of detected corpus lutetium in the present study (16.3, Table 1) is higher than that reported by El-Keraby et al. (1991). The authors found that number of corpora lutea of does treated with 0.2 or $0.4 \mathrm{ml} \mathrm{GnRH}$ ranged between 7.4 and 10.3 in different breeds. Also, with the findings of Gosalvez et al. (1994) reporting number of corpora lutea of 11.0 for rabbit injected with 100 IU PMSG. Meanwhile, it is less than that reported by Lee et al. (1991) stating that number of ovulation points averaged 19.2 /female under PMSG treatment. Using different types of hormonal administration to induce ovulation (superovulation) for the $\mathrm{R}$ and $\mathrm{V}$ line rabbits, Mehaisen et al. (2005) recorded a higher number of ovulation sites (15.3 and 15.9) as compared to 14.3 and 13.8 , in the study of Viudesde-Castro et al. (1995), and 13.5 and 13.2 in the study of Vicente et al. (2003) for R and V lines, respectively. These differences may be due to the effect of the superovulation treatment and breed that were used.

The response to superovulation treatment depends on the type of hormone (Mehaisen et al., 2005) and rabbit breeds (Viudes-de-Castro et al., 1995; Bolet et al., 2000 and Vicente et al., 2003).

Data in Table (2) shows that the proportion of normal embryos was $83.8 \%$ and abnormal embryos was $16.2 \%$ in APRI rabbit line.

The in vivo development viability of the thawed embryos was assessed with the parturition rate and the embryo survival rate in two breed rabbit recipient (Table 3).

A primary problem in the cryopreservation procedures was the proportion of intact embryos (homogeneous cell mass and zona pellucida and mucin coat without damage) after devitrification or Thawing; APRI embryos showed the percentage of intact embryos (transferable), $74.9 \%$ of 187 vitrified embryos and abnormal embryos $11.8 \%$, Table 2 . The recipient does became pregnant 12 days after induce ovulation had been induced $(75 \%)$ in APRI line than $50 \%$ in NZW rabbits. Doe from the vitrified and transfer failed to give birth was $25 \%$ (2/8 rabbits) in APRI line and 50\% (4/8 rabbits) in NZW rabbits (Table 3). The mean number of alive-born by pregnant recipients was $5.37 \pm 1.21$ in APRI Vs $5.65 \pm 1.21$ in NZW, respectively (Table 3). No significant differences were observed between the generations of the APRI and NZW rabbits for the variables analyzed.

Data in Table (4) shows the mean number of embryos transferred and the survival rate at birth both overall and in pregnant recipient does.

When the survival rate at birth was analyzed for APRI recipient does, significant differences were found between the two strains being $(45.1 \%)$ in APRI recipient does $v s(31.9 \%)$ in NZW recipient does. The mean survival rate of pregnant recipient does was $(62.9 \%)$ in NZW recipient does and $(61.5 \%)$ in APRI recipient does.

Maurer and Beier (1976) have observed a higher percentage of survival in Dutch - Belted embryos 
than in NZW embryos (20\% vs. $7 \%$ ), while higher percentage of embryos, irrespective of their genotype and whether they had been frozen, develop in NZW recipient does than in Dutch - Belted recipient does (46\% vs. 26\%). Differences in survival rate of freezing-thawing stresses have recently being observed in mouse strains (Schmidt et al., 1985, 1987 and Pomp and Eisen 1990). Pomp and Eisen, (1990) have found an opposited influence on survival rate between maternal and embryo genotype.

Studies including rabbits (Maurer and Beier, 1976) and rats (Breuel et al., 1993) both showed that PGF had an inhibitory effect on the development of embryos; however, caution was emphasized in drawing comparisons among the species due to differences in embryonic development. PGF seems to prevent the normal compaction process which leads to poorly developed embryos. Embryos exposed to PGF during early development become arrested at the morula stage of development. Embryos may be particularly sensitive to the embryotoxic effects of PGF (Scenna et al., 2004).

In contrast, Putney et al. (1988) reported that the overall mean pregnancy rate was higher for dairy heifers compared to beef heifers, but there were no differences between dairy and beef cows. Also, there were no differences within beef cattle between Brahman and European breed-type recipients. However, it is widely accepted within the ET industry that conception rates are lower in recipients of Bos indicus background, whether pure or crossbred, compared to Bos taurus recipients.

Table 1. Impact of site of ovary on the ovarian structure, ovulation and recovery rates in APRI does

\begin{tabular}{lccccccc}
\hline Site of ovary & $\begin{array}{c}\text { Bleeding } \\
\text { follicles }\end{array}$ & $\begin{array}{c}\text { Large } \\
\text { follicles }\end{array}$ & $\begin{array}{c}\text { Small } \\
\text { follicles }\end{array}$ & $\begin{array}{c}\text { Corpora } \\
\text { lutea }\end{array}$ & Embryo & $\begin{array}{c}\text { Ovulation } \\
\text { rate (\%) }\end{array}$ & $\begin{array}{c}\text { Recovery } \\
\text { rate }(\%)\end{array}$ \\
\hline \multirow{2}{*}{ Right } & 2.78 & 5.28 & 4.61 & 8.22 & 5.83 & 43.21 & 70.9 \\
& \pm 0.87 & \pm 1.14 & \pm 1.16 & \pm 0.46 & \pm 0.78 & \pm 8.88 & \pm 7.8 \\
Left & 3.44 & 4.61 & 4.94 & 8.00 & 6.56 & 51.98 & 81.9 \\
& \pm 1.11 & \pm 0.99 & \pm 1.22 & \pm 0.76 & \pm 0.05 & \pm 8.43 & \pm 7.4 \\
Total & 6.22 & 9.89 & 9.56 & 16.28 & 12.39 & 47.34 & 76.10 \\
& \pm 1.98 & \pm 2.13 & \pm 2.38 & \pm 1.12 & \pm 0.83 & \pm 17.31 & \pm 16.2 \\
\hline
\end{tabular}

Recovery rates $=$ Embryos $/ C L * 100$

Ovulation rate $=($ Embryos $/ \mathrm{CL}+\mathrm{LF}) * 100$

Table 2. Recovery rate of flushing APRI rabbit embryo (normal and abnormal) and after cryopreservation by viterification method

\begin{tabular}{lcc}
\hline \multicolumn{1}{c}{ Items } & $\mathrm{N}$ & Recovery rates \\
\hline Animal & 18 & $\%$ \\
Corpora lutea & 293 & - \\
Total embryo & 223 & 76.1 \\
Normal & 187 & 63.8 \\
Abnormal & 36 & 12.3 \\
Vitrified & & - \\
Total vitrified embryo & 187 & 86.7 \\
Total embryo Recovery & 162 & 74.9 \\
Transferable (Normal) & 140 & 11.8 \\
Abnormal & 22 & \\
\hline
\end{tabular}

Table 3. Pregnancy rate and bunnies per doe in recipient APRI and NZW does

\begin{tabular}{cccc}
\hline Breed & Number of recipients & Pregnancy rate (\%) & Bunnies/doe \\
\hline APRI & 8 & 75 & $5.37 \pm 1.21$ \\
NZW & 8 & 50 & $5.65 \pm 1.21$ \\
\hline
\end{tabular}


Table 4. Survival rate (\%) of freezing APRI embryos in terms of recipient and embryonic genotype

\begin{tabular}{cccc}
\hline Breed & Does & Transferred embryos & Survival rate $(\%)$ \\
\hline \multirow{2}{*}{ APRI } & 8 & $8.9 \pm 0.7$ & 45.1 \\
NZW & 8 & $(71)$ & $(32)$ \\
& & $8.6 \pm 0.5$ & 31.9 \\
& & $(69)$ & $(22)$ \\
APRI & 6 & Pregnant recipient does & 61.5 \\
& \multirow{2}{*}{ NZW } & $4.71 \pm 0.6$ & $(32)$ \\
& 4 & $(52)$ & 62.9 \\
\end{tabular}

Garcia et al. (2000) observed differences in the survival rate at birth between vitrified embryos belonging to lines $\mathrm{V}$ and $\mathrm{R}(43 \%$ vs. $22 \%$, respectively). Probably due to the recipient genotype; in this respect, Vicente et al. (2003) transferred the vitrified embryos in a pool of recipient does of undefined genetic origin in a Uruguayan rabbit farm. This last aspect is another important factor in rabbits assessed by Vicente and Garcia-Ximénez (1993) and Joly et al. (1996).Obtain high fertility and survival rates, line $\mathrm{V}$ and line 1077 seemed to be better recipients than the lines which have NZW origin.

The hCG has been used to stimulate ovulation or to reinforce coital stimulation in rabbits. A nonreceptive doe that ovulates in response to hCG treatment shows insufficiently developed oviducts and uterus and a lower probability of becoming pregnant (Moody and McNitt, 1988). Bolet and Theau-Clement (1988) obtained success rates of implanted embryos (65 and $74 \%$, respectively), but they carried out their evaluations on the $17^{\text {th }}$ and $14^{\text {th }}$ days of gestation, respectively. The proportion of implanted embryos observed by Vicente and GarciaXimenez (1991) was 68\%.

Besides the different times to the onset of oestrus recorded in different ruminant breeds, breed has been indicated as a major factor contributing to the variation recorded in the ovarian response to superovulation (Donaldson, 1984; Vivanco et al., 1994 and Ammoun et al., 2006). In cattle, sheep and goats the number of corpora lutea recorded and number of transferable embryos recovered following superovulation differ between breeds (Donaldson, 1984; Baril et al., 1989; Goel and Agrawal, 2005 and Ammoun et al., 2006). In goats for example, a higher number of embryos (average of 10.1) was recovered in Alpine does, compared to Angora does (Average of 7.5) (Baril et al., 1989). In addition, a higher refractoriness was recorded in Alpine goats, compared to Nubian goats following superovulation (Nuti et al., 1987). However, the breed effect has been associated with the different prolificacy of the breeds, where a high prolific breed has been reported to respond better to exogenous gonadotrophins (Bindon et al., 1986). It has also been found that sheep selected for prolificacy tend to be more sensitive to gonadotrophin treatment (Kelly et al.,
1983 and Bindon et al., 1986). In contrast, Picazo et al. (1996) failed to establish a clear breed difference in ovarian response in three sheep breeds superovulated with FSH.

Genotype has been recognized to have a major effect on ovarian follicular development. Even though gonadotrophin treatment increases the follicular development in all breeds, the numbers of ovarian follicles which are recruited to ovulate differ in the different breeds (Ammoun et al., 2006).

\section{CONCLUSION}

The survival rate of freezing embryos of the APRI strain increased when they were transferred to recipient does of the APRI strain. In this case a pregnancy rate of $75 \%$ and a survival rate of $45.1 \%$ at birth were obtained. Survival rate was improved in APRI recipient does attaining $45.1 \%$ vs. $31.9 \%$ in NZW recipient does.

\section{REFERENCES}

Ali, Rania R.H., 2010. Recovery rate and quality of rabbit embryos as affected by frequency of surgical. M.Sc. Mansoura Univ. Fac. Agric., Egypt.

Ammoun, I., T. Encinas, A. Veiga-Lopez, J.M.Ros, I. Contreras, P. Gonzalez-Anover, M.J. Cocero, A.S. McNeilly and Gonzalez-Bulnes, 2006. Effects of breed on kinetics of ovine FSH and ovarian response in superovulated sheep . Theriogenology, 66: 896-905.

Baril, B., P. Casamitjana, J. Perrin and J.C.Vallet, 1989. Embryo production, freezing and transfer in Angora, Alpine and Saanen goats. Zuchthygiene, 24:101-115.

Bindon, B.M., L.R Piper, L.P. Cahill, M.A.Driancourt and T. O'Shea, 1986. Genetic and hormonal factors affecting superovulation. Theriogenology, 25: 53-70.

Bolet, G. and M. Theau-Clement, 1988 Timing of embryonic development in two rabbit strains. In: Proc. $11^{\text {th }}$ Cong. On Animal Reproduction and Artificial Insemination, Dublin, 3: 391.

Bolet, G., J. M. Brun, M. Monnerot, F. Abeni, C. Arnal, J. Arnold, D. Bell, G. Bergoglio, U. 
Besenfelder, S. Bosze, S. Boucher, N. Chanteloup, M.C. Ducourouble, M. DurandTardif, P.J. Esteves, N. Ferrand, A. Gautier, C. Haas, G. Hewitt, N. Jehl, T. Joly, P.F. Koehl, T. Laube, S. Lechevestrier, M. Lopez, G. Masoero, J.J. Menigoz, R. Piccinin, G. Queney, G. Saleil, A. Surridge, W. Van Der Loo, J.S. Vicente, M.P. Viudes De Castro, J.S. Virag and J.M. Zimmermann, 2000. Evaluation and conservation of european rabbit (Oryctolaguscuniculus) genetic resources. First results and inferences $7^{\text {th }}$ World Rabbit Cong, Valencia, Journal Rabbit Science Association (Suppl. 1), 8: 281-315.

Bourdage, R.J. and S.A. Halbert, 1988. Distribution of embryos and 500- $\mu \mathrm{m}$ microspheres in the rabbit oviduct: Control for acute motion analysis during transport. Biology of Reproduction, 38: 282-291.

Breuel, K.F., A. Fukuda and F.N. Schrick, 1993. Effect of prostaglandin F2alpha on development of 8-cell rat embryos in vitro. Biology of Reproduction, 48: 173.

Dobrinsky, J.R., 2001. Cryopreservation of swine embryos: a chilly past with a vitrifying future. Theriogenology, 56: 1333-1344.

Donaldson, L.E., 1984. Cattle breed as source of variation in embryo transfer. Theriogenology, 21: 1013-1018.

El-Keraby, F., Tork M. Dorra, A.I. Abd El-Ghani and S.A. Fawzy, 1991. Effect of GnRH administration rate and embryo recovery in some rabbit breeds. Journal of Agriculture Science Mansoura Univ., 16 (8); 1749.

Garcia, M.L., O. Blumetto, G. Capra, J.S. Vicente and M. Baselga, 2000. Vitrified embryos transfer of two selected Spanish rabbit lines to Uruguay. Proc. $7^{\text {th }}$ World Rabbit Cong. A: 139-142.

Goel, A.K. and K.P. Agrawal, 2005. Ovulatory response and embryo yield in Jakhrana goats following treatments with PMSG and FSH. Tropical Animal Health and Production, 37: 549558.

Gosalvez, L.F., J.M.R. Alvarino, P. Diaz and M. Tor, 1994. Influence of age, stimulation by PMSG or flushing on the ovarian response to LHRHa in young rabbit females. World Rabbit Science, 2: 41-45.

Joly, T., J.S. Vicente, M. Theau-Clèment, F. GarciaXiménez, U. Besenfelder, and J.P. Renard, 1996. Cryopreservation of genetic resources in rabbit species: practical application. Proc. $6^{\text {th }}$ World Rabbit Cong., 2: 293-298.

Kelly, R.W., K.E. Thompson, H. Hawker, S.F. Crosbie, and J.C. McEwan, 1983. Live weight, ovulation rate and wool growth responses of light and heavy ewes to differential feeding. N. Z. J. Expe. Agric., 11: 219-224.

Lee, T.S., K.T. Lim and J.S. Na, 1991. Superovulation treatment and short term storage of embryos in domestic rabbit. Korean Journal of Animal Science, 33: 18-24.

Leoni, G., F. Berlinguer, I, Roseti, L. Bogliolo, S. Ledda and S. Naitana, 2003. Resumption of metabolic activity of vitrified/warmed ovine embryos. Molecular Reproduction and Development, 64: 207-213.

Lopez-bejar, M., and F. Lopez-gatius, 2000. In vitro and in vivo survival of vitrified rabbit embryos. Theriogenology, 53: 259 (Abstr).

Maurer, P.R. and H.M. Beier, 1976. Uterine proteins and development in vitro of rabbit preimplantation embryos. Journal of reproduction and fertility, 48:33-41.

Mehaisen, G.M.K., J.S. Vicente, R. Lavaraa and M.P. Viudes-de- astrob, 2005. Effect of eCG dose and ovulation induction treatments on embryo recovery and in vitro development postvitrification in two selected lines of rabbit does. Animal Reproduction Science, 90: 175-84.

Moody, J.R. and J.I. McNitt, 1988. Vulva color in rabbits as indicator of probable reproductive performance. Journal of Animal Science, 66: 67 (Abstr.)

Nuti, L.C., B.S. Minhas, W.C. Baker, J.S. Capehart and P. Marrack, 1987. Superovulation and recovery of zygotes from Nubian and Alpine dairy goats. Theriogenology, 28: 481-488.

Ogawa, S. and S. Tomoda, 1976. Survival of 16celled and morula stage rabbit embryos frozen. Experimental Animals, 25: 273-282.

Papis, K., J. Sypecka, M. Korwin-Kossakowski, Elzbieta Wenta-Muchalska and B. Bilska, 2005. Banking of embryos of mutated, paralytictremor rabbit by means of vitrification. Lab Animal, 39: 284-289.

Picazo, R.A., M.J. Cocero, M.L. Barragan and A.L. Sebastian, 1996. Effects of LH administration at the end of an FSH superovulatory regimen on ovulation rate and embryo production in three breeds of sheep. Theriogenology, 45: 1065-1073.

Pomp, D. and E. J. Eisen, 1990. Genetic control of survival of frozen mouse embryos. Biology of Reproduction, 42: 775-786.

Putney, D.J., W.W. Thatcher, M. Drost, J.M. Wright and M.A. DeLorenzo, 1988. Influence of environmental temperature on reproductive performance of bovine embryo donors and recipients in the southwest region of the United States. Theriogenology, 30: 905-922.

Scenna, F.N., J.L. Edwards, N.R. Rohrbach, M.E. Hockett, A.M. Saxton and F.N. Schrick, 2004. Detrimental effects of prostaglandin F2 Alpha on preimplantation bovine embryos. Prostaglandins and other Lipid Mediators, 73: 215-226.

Schmidt, P.M., C.T. Hansen and DE Wildt, 1985. Viability of frozen -thawed mouse embryos as affected by genotype. Biology of Reproduction, 32: 507-514. 
Schmidt, P.M., M.C. Schiewe and D.E. Wildt, 1987. The genotype response of mouse embryos to multiple freezing variables. Biology of Reproduction, 37: 121-1128.

Vicente, J.S., 2008. Rabbit embryo production and conservation. World Rabbit Sci., 16: 51 - 61

Vicente, J.S. and F. Garcia-Ximénez, 1993. Effects of two cryoprotective agents used in slow or rapid standard freeze-thaw procedure on the in vivo survival of morulae from three rabbit strains. INIA, 8: 247-256.

Vicente, J.S. and F. Garcia-Ximenez, 1991. Effects of hCG treatment on morula recovery in the rabbit and their survival after synchronous transfer. Animal Reproduction Science, 24: 347 353.

Vicente, J.S., M.P. Viudes de castro and M.L. García, 1999. In vivo survival rate of rabbitmorulae after vitrification in a medium without serum protein. Reproduction Nutrition Development, 39: 657-662.

Vicente, J.S., M.P. Viudes-DE-Castro, M.L. Garcia and M. Baselga, 2003. Effect of rabbit line on a program of cryopreserved embryos by vitrification. Reproduction Nutrition Development, 43: 137-143.

Viudes-de-Castro, M.P., F. García-Ximénez and J.S. Vicente, 1995. Embryo recovery from eliminating does of three selected rabbit strains for an embryo bank, Investigación Agraria: Production Sanidad Animal, 10: 145-152.

Vivanco, H.M., K.B. Greany and H. Varela, 1994. Explaining the variability in superovulatory responses and yield of transferable embryos in sheep embryo transfer. Theriogenology, 41: 329 (Abstr.).

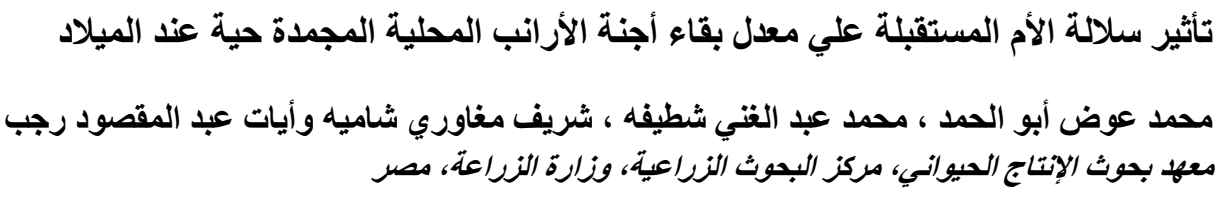

يهدف هذا البحث الي دراسة تأثير التركيب الجيني لأر انب النيوزيلاندي الأبيض والأبري علي معدل بقاء أجنة أر انب الأبرى المجمدة عند

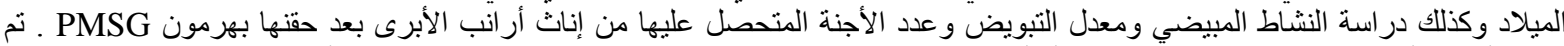

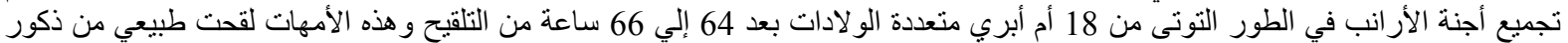

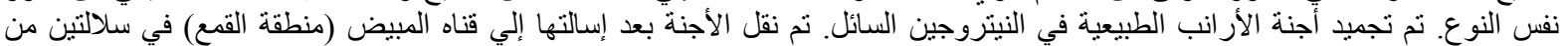

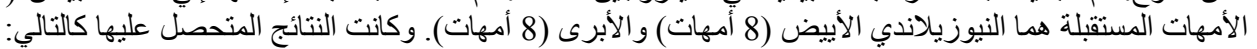

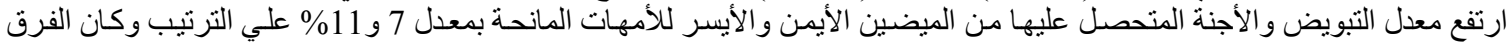

بينهما غير معنوي. منوسط عدي عدد الأجنة المتحصل عليها من أمهات الأبرى

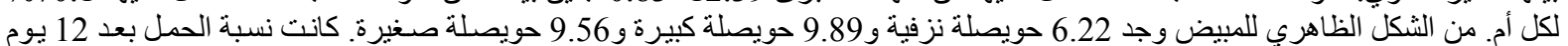

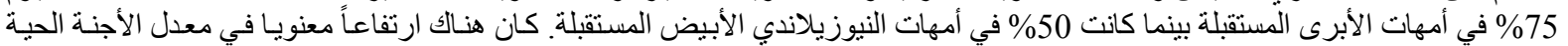

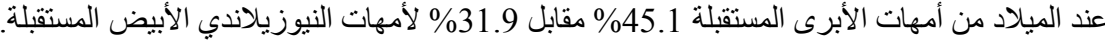
يتضح من هذه الدر اسة كفاءة أمهات الأبري كأمهات مانحة للأجنة لأمهات مستقبلة. 